\title{
Bemerkung zu meiner Arbeit: \\ Beiträge zur Wellenoptik... und zur Optik bewegter Körper*.
}

\author{
Von Johannes Picht in Potsdam-Neubabelsberg.
}

(Eingegangen am 29. Januar 1930.)

Herr Prof. v. Laue macht mich freundlichst darauf aufmerksam, daß die unter 5. und 6. erhaltenen Ergebnisse, die sich auf Reflexion und Brechung an einer rotierenden Ebene beziehen, nicht mehr der Wellengleichung $\Delta u-\frac{1}{c^{2}} \frac{d^{2} u}{d t^{2}}=0$ genügen, mithin also falsch sein müssen. Ich danke Herrn Prof. v. Laue für diesen Hinweis und hoffe, in einiger Zeit auf die hiernach noch offene Frage zurückkommen zu können. Vorläufig stehen sich demnach die beiden geometrisch-optisch erhaltenen Ergebnisse, die in der obengenannten Arbeit unter "Bemerkungen zur Reflexion am rotierendèn ebenen Spiegel" angeführt (nach H. A. Lorentz) bzw. abgeleitet wurden und die beide eine (allerdings verschiedene) Fokalwirkung des rotierenden ebenen Spiegels behaupten, einander widersprechend gegenüber.

Neubabelsberg, den 25. Januar 1930.

* ZS. f. Phys. 58, 667, 1929. 